\title{
Relationships between two types of reputational concern and altruistic behavior in daily life
}

$\operatorname{AUTHOR}(\mathrm{S}):$

Kawamura, Yuta; Kusumi, Takashi

\section{CITATION:}

Kawamura, Yuta ... [et al]. Relationships between two types of reputational concern and altruistic behavior in daily life. Personality and Individual Differences 2018, 121: 19-24

\section{ISSUE DATE:}

2018-01-15

URL:

http://hdl.handle.net/2433/228310

\section{RIGHT:}

(c) 2017. This manuscript version is made available under the CC-BY-NC-ND 4.0 license

http://creativecommons.org/licenses/by-nc-nd/4.0/; The full-text file will be made open to the public on 15 January 2020 in accordance with publisher's 'Terms and Conditions for Self-Archiving'.; この論文は出版社版でありません。引 用の際には出版社版をご確認ご利用ください。; This is not the published version. Please cite only the published version. 
Personality and Individual Differences, vol. 121, 19-24, 2018

DOI: 10.1016/j.paid.2017.09.003

Relationships between two types of reputational concern and altruistic behavior in daily life

(author version)

Yuta Kawamura $^{1,2}$, Takashi Kusumi ${ }^{1}$

${ }^{1}$ Graduate School of Education, Kyoto University, Japan.

${ }^{2}$ Japan Society for the Promotion of Science, Tokyo, Japan

Correspondence should be addressed to:

Yuta Kawamura

Department of Education, Kyoto University

Yoshida-honmachi, Sakyo-ku, Kyoto 606-8501, Japan.

E-mail address: kawamura.yuta.83c@st.kyoto-u.ac.jp 


\begin{abstract}
Although many studies have shown that reputational cues promote altruism, few studies have focused on individual differences. The present study provides novel evidence indicating that the relationship between reputational concern and altruistic behavior differs according to the type of reputational concern involved and the recipients of altruism. Specifically, the relationships between individual differences of two reputational concerns (i.e., praise seeking and rejection avoidance) and the frequency with which participants exhibited altruistic behavior toward various individuals (i.e., family members, friends/acquaintances, and strangers) were examined. As predicted, neither type of reputational concern was significantly associated with altruistic behavior toward family members. This is understandable, as altruistic behavior toward familiar people is unlikely to lead to a good reputation. Conversely, praise seeking predicted altruistic behavior toward friends/acquaintances and strangers, whereas rejection avoidance did not. These findings are consistent with recent literature suggesting the effectiveness of positive reputation systems to promote generosity, relative to negative reputation systems. Furthermore, rejection avoidance was negatively associated with altruistic behavior toward strangers; we discussed the possibility that this was because such behavior was not very normative. Our findings provide useful insight for future studies examining the relationship between reputation and altruistic behavior.
\end{abstract}

Keywords: altruism; reputational concern; generosity; praise seeking; rejection avoidance; social norms 
Relationships between two types of reputational concern and altruistic behavior in daily life

\section{Introduction}

Altruistic behavior, which is behaviorally defined as the tendency to benefit others at the expense of one's own resources (e.g., Fehr \& Fischbacher, 2003), usually leads to a good reputation (e.g., Bereczkei, Birkas, \& Kerekes, 2007, 2010; Hardy \& Van Vugt, 2006). An individual with a good reputation tends to obtain future rewards such as interaction partners (e.g., Barclay \& Willer, 2007; Sylwester \& Roberts, 2010) or romantic mates (e.g., Arnocky, Piche, Albert, Ouellette, \& Barclay, 2017; Barclay, 2010; Phillips, Barnard, Ferguson, \& Reader, 2008). These reputational benefits could serve as an incentive for altruistic behavior (for a review, see Barclay, 2012). The present study focuses on the relationship between reputational concern and altruistic behavior.

\section{1 Reputation and altruistic behavior}

First, we explain why reputation and altruism are closely related from an evolutionary psychological perspective. One important characteristic of human beings is that we behave altruistically with each other, including genetically unrelated others. However, this is somewhat peculiar because the existence of free riders would prevent the evolution of altruism. If some selfish people gain benefits without behaving altruistically, they may have higher survival and reproductive rates than altruistic individuals. Therefore, some mechanisms that detect and ostracize free riding may underlie the evolution of altruism; one crucial mechanism is reputation (Fehr, 2004). By favoring individuals with a good reputation and rejecting individuals with a bad reputation, the prosperity of free riders can be prevented. Thus, reputation may have an 
important role in the evolution of altruism even toward genetically unrelated individuals (for a review, see Barclay, 2012).

Previous empirical studies have shown that individuals tend to respond to reputational cues sensitively in deciding whether to behave altruistically. For example, people are more likely to behave generously when their behavior is observed by others (e.g., Barclay \& Willer, 2007; Hardy \& Van Vugt, 2006; Milinski, Semmann, \& Krambeck, 2002). One study has showed that contributions toward public goods increased when contribution amounts were observed by others (Hardy \& Van Vugt, 2006). Similarly, people competed to be more generous when their behavior could affect the decisions of future interaction partners (Barclay \& Willer, 2007). The effects of visibility on the promotion of altruism have also been observed in more realistic situations including those involving charity (Bereczkei et al., 2007, 2010). Moreover, people become more generous in situations where others are likely to gossip (e.g., Piazza \& Bering, 2008; Wu, Balliet, \& Van Lange, 2016a).

While numerous studies have shown that situational factors that activated reputational concern promoted altruism, the relationship between individual differences in reputational concern and the frequency of altruistic behavior has not been examined. However, some studies imply that there are individual differences in the sensitivity to reputation (i.e., reputational concern), which could affect altruistic behavior (c.f., Barclay, 2012). For example, one study showed that, although the mean contribution amount toward public goods increased when individual contributions could be identified, the number of non-contributors did not differ based on whether they were identifiable or anonymous (Rege \& Telle, 2004). This may be because non-contributors are not very 
sensitive to their reputation. Additionally, adults with autism spectrum disorders (ASD) did not change their charitable donation amount regardless of the presence of an observer (Izuma, Matsumoto, Camerer, \& Adolphs, 2011). The study suggested that this is probably because people with ASD are insensitive to reputation during altruistic decisionmaking. In contrary, narcissism is positively related to altruistic behavior in public (Konrath, Ho, \& Zarins, 2016). Although narcissists lack regard for others, they also have characteristics of seeking administration and status (Campbell \& Foster, 2007). This suggests that narcissists behave generously in public because they are sensitive about their reputation. Although these studies did not directly examine the individual differences in reputational concerns, these findings imply that reputational concern could be related to altruism. Here, we directly examine this possibility.

\section{2 Two types of reputational concern: praise seeking and rejection avoidance}

There are two types of reputational concern (e.g., Kawamura \& Kusumi, 2017; Wu, Balliet, \& Van Lange, 2016b): seeking a good reputation (i.e., praise seeking) and avoiding a bad reputation (i.e., rejection avoidance). These concerns are distinctive; one study has showed that these concerns predict different types of response to one's evaluation from others (Kojima, Ohta, \& Sugawara, 2003). The relationships between these types of reputational concern and altruistic behavior could also differ. In terms of praise seeking, it may be positively related to altruistic behavior. As described above, altruistic behavior generally leads to a good reputation. Given that the concern for seeking a good reputation promotes behavior that leads to such a reputation, it would be positively related to altruistic behavior. In contrast, the individual difference of rejection avoidance is not much positively related to altruistic behavior as it is to praise seeking. By definition, 
people with high rejection avoidance may be motivated not to take actions that would be disliked by others. This purpose can be achieved by merely suppressing selfish behavior; to avoid rejection, people only need to ensure that they are not more selfish than others and do not actually have to behave more altruistically than others. Corresponding to these notions, one study showed that eye-like image (i.e., subtle cue suggestion that one is being watched) promoted altruistic behavior, and this effect was mediated by the expectation of a good reputation rather than concern about punishment (Oda, Niwa, Honma, \& Hiraishi, 2011). In addition, a recent review suggested that positive reputation systems (e.g., awards and certificates) were more efficient in promoting generosity, relative to negative reputation systems, in modern society (Wu et al., 2016b). Therefore, we consider that praise seeking, rather than rejection avoidance, could be related to altruistic behavior.

\section{3 Difference in altruistic behavior according to the recipient}

Altruistic behavior could differ according to the recipient of the altruism; for example, people's altruistic behavior toward family members, friends/acquaintances, and strangers could differ. Previous research has suggested that the relationship between psychological traits (e.g., Big Five personality traits) and altruistic behavior differed according to the recipient of altruism (e.g., Oda et al., 2014). Regarding the relationships between reputational concern and altruistic behavior, previous research has suggested that altruistic behavior toward familiar recipients, relative to altruistic behavior toward distant recipients, is less likely to result in a good reputation. One study showed that charitable donors with personal connections to recipients were considered less charitable relative to those without this connection (Lin-Healy \& Small, 2012). Therefore, altruistic behavior toward familiar people (e.g., family members) is less likely to be associated with 
reputational concern relative to altruistic behavior toward distant recipients (e.g., strangers).

This hypothesis is also supported by the evolutionary perspective, whereby the evolution of altruism toward family or friends/acquaintances can be explained by factors other than reputation. For example, the kin selection mechanism could explain the evolution of altruism toward family members (Hamilton, 1964), in that individuals who help their genetic relatives are likely to pass their own genes on the next generation. Altruistic behavior toward friends/acquaintances could also be explained by direct reciprocity (Trivers, 1971), whereby recipients repay the altruistic individual directly. However, altruism toward strangers is unlikely to lead to genetic or direct benefits; the evolution of this type of altruistic behavior is explained only by future benefits gained via reputation. Therefore, the proportion of the variance in altruism toward strangers explained by reputational concern is likely to be larger relative to that explained by altruistic behavior toward family members or friends/acquaintances.

\section{4 Aim and Hypotheses}

The current study examined the relationships between two types of reputational concern and altruistic behavior. Our hypotheses are described below:

Hypothesis 1: Praise seeking will be positively associated with altruistic behavior, but rejection avoidance will not.

Hypothesis 2: The strength of the relationship between praise seeking and altruistic behavior will increase as the social distance between the recipient and the 
individual performing the altruistic behavior increases.

\section{Method}

\subsection{Participants and procedure}

We recruited 416 Japanese participants (208 men and 208 women) aged between 20 and 59 years $(M=39.8, S D=11.13)$, using the Macromill online research system (Macromill, Inc. Tokyo, Japan). Participants completed the Praise Seeking and Rejection Avoidance Need Scales (PSRA; Kojima et al., 2003), Self-Report Altruism Scale Distinguished by the Recipient (SRAS-DR; Oda et al., 2013), and Interpersonal Reactivity Index (IRI; Davis, 1980; translated into Japanese by Himichi et al., 2017). Although they also answered another questionnaire, we did not report the results, as these questionnaires were used for a different purpose. The present study was approved by the ethics committee at the institution with which the authors were affiliated.

\subsection{Measures}

\subsubsection{Praise Seeking and Rejection Avoidance Need Scales (PSRA)}

The 18-item Praise Seeking and Rejection Avoidance Need Scales were used to measure praise seeking and rejection avoidance (Kojima et al., 2003). Participants are required to indicate the extent to which they agree with statements regarding the tendency to seek positive evaluation (i.e., praise seeking) and avoid negative evaluation (i.e., rejection avoidance) from others. Sample items include "When I work with someone, I am eager to advertise my good points" (i.e., praise seeking) and "When I express my opinion, I am afraid of hearing a dissident voice" (i.e., rejection avoidance). There was no reverse item in this scale. Higher mean scores represent greater reputational concern. 
Responses are provided using a five-point Likert scale ranging from 1 (disagree) to 5 (agree).

\subsubsection{Self-Report Altruism Scale Distinguished by the Recipient (SRAS-DR)}

The 21-item SRAS-DR (Oda et al., 2013) was used to assess the frequency with which participants engaged in altruistic behavior. The scale consists of three subscales, which measure altruistic behavior toward family members, friends/acquaintances, and strangers. Responses are provided using a five-point Likert scale ranging from 1 (never) to 5 (very often). Sample items include "I have supported one of my family members when they were not feeling well" (i.e., family members), "I have listened to the troubles and complaints of a friend/acquaintance" (i.e., friends/acquaintances), "I have helped a stranger who fell on the road" (i.e., strangers). There was no reverse item in this scale. Higher mean scores represent higher frequency of the altruistic behavior. The English version of the scale can be viewed in Table 1 of an article published by Oda, Shibata, Kiyonari, Takeda, and Matsumoto-Oda (2013).

\subsubsection{Interpersonal Reactivity Index (IRI)}

The IRI (Davis, 1980; Himichi et al., 2017) was used to assess participants' dispositional empathy. In examining the relationship between reputational concern and altruistic behavior, we control for individual differences in empathic traits, as empathy can affect altruistic behavior (e.g., Batson, 2011). The questionnaire consists of 28 items divided into the following four subscales: Fantasy Scale assessing the tendency to become involved in fictional situations (e.g., "When I watch a good movie, I can very easily put myself in the place of a leading character"), Perspective Taking assessing the tendency to 
take the perspectives of others (e.g., "Before criticizing somebody, I try to imagine how I would feel if I were in their place"), Empathic Concern assessing the tendency to feel concern for others (e.g., "I often have tender, concerned feelings for people less fortunate than me"), and Personal Distress assessing the tendency to feel anxiety or discomfort in emotional situations (e.g., "When I see someone who badly needs help in an emergency, I go to pieces"). Responses are provided using a five-point scale ranging from 1 (does not describe me very well) to 5 (describes me very well). Nine items were reverse coded such that higher scores reflect higher levels of empathic traits.

\subsection{Data analysis}

We conducted a series of hierarchical multiple regression analyses on altruistic behavior for each recipient. The control variables (i.e., age, sex, and the sub-components of empathy) were entered into the model during Step 1, and the two types of reputational concern (i.e., praise seeking and rejection avoidance) were included in Step 2 (Table 2). Table S1 presents the regression model that did not include empathic traits. Data were analyzed using $\mathrm{R}$ version 3.2.5.

\section{Results}

\subsection{Descriptive statistics}

Table 1 shows means, standard deviations, Cronbach's alpha coefficients, and the correlations between variables.

Participants' mean SRAS-DR scores differed significantly according to the recipient of the altruism. The results of the one-way repeated measures ANOVA 
examining altruistic behavior showed a significant main effect of recipient, $F(2,830)=$ 613.23, $p<.001, \eta_{p}^{2}=.60$. Holm's multiple comparisons showed that the frequency with which participants engaged in altruistic behavior toward family members was higher relative to that observed for friends/acquaintances, $t(415)=11.30, p<.001$, and strangers, $t(415)=30.44, p<.001$. In addition, the frequency with which participants engaged in altruistic behavior toward friends/acquaintances was higher relative to that observed for strangers, $t(415)=23.87, p<.001$.

The correlation analysis showed that praise seeking was not significantly correlated with altruistic behavior toward family members $(r=.08, p=.109$; see Table 1). In contrast, praise seeking was positively correlated with altruistic behavior toward friends/acquaintances $(r=.14, p=.004)$ and strangers $(r=.23, p<.001)$. In addition, rejection avoidance was not significantly correlated with altruistic behavior toward family members $(r=.02, p=.662)$ or friends/acquaintances $(r=.07, p=.173)$. However, it was negatively correlated with altruistic behavior toward strangers $(r=-.17, p<.001)$.

\subsection{Hierarchical multiple regression analysis}

Hierarchical multiple regression analysis on altruistic behavior for each recipient were conducted (see Table 2). The Variance Inflation Factor (VIF) scores of the variables for all regression models were lower than 1.65 , which suggests that multicollinearity was not a concern. As covariate variables, four subscales of empathic traits were included in all models in addition to sex and age. Empathic concern and perspective taking tend to be related positively to altruistic behavior. In contrast, Fantasy scale and personal distress were unrelated or negatively related to altruistic behavior. These results are consistent 
with the definition that empathic concern and perspective taking have other-oriented aspects, whereas fantasy scale and personal distress do not (see the introduction of Konrath, O'Brien, \& Hsing, 2011).

As expected, the results demonstrated that the relationship between reputational concern and altruistic behavior differed according to the type of reputational concern involved and the recipient of the altruistic behavior. After controlling for demographic variables and empathic traits, reputational concern did not explain a significant proportion of the variance in altruistic behavior toward family members $\left(\Delta R^{2}=.01, F(2,407)=1.84\right.$, $p=.160)$. Neither praise seeking, $\beta=.08,95 \% \mathrm{CI}=[-.01, .18], p=.093$, nor rejection avoidance, $\beta=.03,95 \% \mathrm{CI}=[-.08, .15], p=.545$, predicted altruistic behavior. However, reputational concern explained a significant proportion of the variance in altruistic behavior toward friends/acquaintances $\left(\Delta R^{2}=.01, F(2,407)=3.08, p=.047\right)$. In addition, praise seeking was a significant predictor of altruistic behavior toward friends/acquaintances, $\beta=.11,95 \% \mathrm{CI}=[.02, .20], p=.016$, but rejection avoidance was not, $\beta=.01,95 \% \mathrm{CI}=[-.10, .11], p=.916$. Furthermore, reputational concern explained a significant proportion of the variance in altruistic behavior toward strangers $\left(\Delta R^{2}=.07\right.$, $F(2,407)=16.89, p<.001)$. Moreover, praise seeking was a significant positive predictor, $\beta=.25,95 \% \mathrm{CI}=[.15, .34], p<.001$, and rejection avoidance was a significant negative predictor, $\beta=-.20,95 \% \mathrm{CI}=[-.31,-.09], p<.001$, of altruistic behavior toward strangers.

\section{Discussion}

The current study examined the relationships between two types of reputational concern and altruistic behavior. As predicted in Hypothesis 1, the relationship between reputational concern and altruistic behavior differed according to the type of reputational 
concern involved. The results showed that praise seeking was positively related to altruistic behavior, but rejection avoidance was not. These findings are consistent with those of a previous study that suggested that positive reputation systems may be more effective in promoting generosity than negative reputation systems (Wu et al., 2016b). Furthermore, the results indicated that the relationship between reputational concern and altruistic behavior differed according to the recipient of the altruism, which supported Hypothesis 2. Praise seeking was not associated with altruistic behavior toward family members; however, it was associated with altruistic behavior toward friends/acquaintances and strangers. Moreover, the relationship between praise seeking and altruistic behavior toward strangers was stronger relative to that between praise seeking and altruistic behavior toward friends/acquaintances. These results are consistent with those of a previous study, which showed that altruistic behavior toward personally connected recipients was considered less charitable relative to altruistic behavior toward distant recipients (Lin-Healy \& Small, 2012). The results of the present study could have occurred because altruism toward family members, relative to altruistic behavior toward strangers, is less likely to lead to a good reputation. These results are also consistent with evolutionary theory, as previous studies suggested that altruism toward strangers could be explained only by future benefits gained via reputation (e.g., Barclay, 2012).

Unexpectedly, rejection avoidance was negatively correlated with altruistic behavior toward strangers. Given that altruism generally leads to a good reputation, this finding is difficult to explain. However, some studies have shown that altruists occasionally have negative reputations or experience punishment from observers. For example, in some cultures, individuals were punished for both selfish and altruistic 
behavior (Herrmann, Thoni, \& Gachter, 2008). Additionally, people who contributed extremely to a public good were evaluated negatively by others (Parks \& Stone, 2010). Therefore, altruistic behavior toward strangers could have been negatively correlated with rejection avoidance because it occasionally creates a bad reputation.

Why does altruism occasionally lead to a bad reputation? One explanation could involve social norms. For example, Herrmann et al. (2008) found that individuals who exhibited altruistic behavior were punished in cultures that cooperative behavior is not very normative. Similarly, Parks and Stone (2010) suggested that people evaluated altruism negatively, partly because they regarded extremely generous individuals as norm violators. Therefore, altruistic behavior could lead to a bad reputation when altruism was not normative. These findings provide a suitable explanation for the results of the current study, as altruistic behavior toward strangers could have been less normative relative to altruistic behavior toward family members or friends/acquaintances. In fact, the mean score reflecting the frequency with which participants exhibited altruistic behavior toward strangers was lower relative to those observed for altruistic behavior toward family members or friends/acquaintances (Table 1). Therefore, as altruistic behavior toward strangers was not normative, it could have created a bad reputation. People with high levels of rejection avoidance are likely to focus on the possibility that they have been evaluated negatively, even if altruism generally creates a good reputation. This could explain why rejection avoidance was negatively associated with altruistic behavior toward strangers. Future research is required to examine this issue directly.

Although the results were theoretically consistent with those of previous studies, 
the current study was subject to some limitations. For example, altruistic behavior was measured via a self-report questionnaire; therefore, participants with strong reputational concern could have exaggerated the frequency with which they exhibited altruistic behavior, and the question as to whether they had actually behaved altruistically in reallife interactions remains unclear. In addition, since this is a correlational study, inference regarding the causal effect of reputational concern on altruistic behavior was limited. Although one of the strengths of using SRAS-DR is that it covers the wide range of altruistic behavior in daily life, future research should examine real behavior. Additionally, the study did not consider cultural differences. Previous research showed that Japanese people exhibited higher levels of rejection avoidance relative to those observed in American individuals (Hashimoto \& Yamagishi, 2013). Therefore, as the current study included only Japanese participants, the findings might not be generalizable to other populations. Future studies should examine the relationship between reputational concern and altruistic behavior in various cultural contexts to increase the generalizability of the findings.

Despite the limitations noted above, the study provides novel evidence indicating that the relationship between reputational concern and altruistic behavior differed according to the type of reputational concern involved and the recipients of altruism. The strength of this relationship increased as the social distance between the recipient and the individual performing the altruistic behavior increased. In addition, the relationship differed according to the type of concern involved: praise seeking was positively associated with altruistic behavior toward friends/acquaintances and strangers; however, rejection avoidance was not associated with altruistic behavior toward family and 
friends/acquaintances and negatively associated with altruistic behavior toward strangers. These findings provide useful insight for future study examining the relationship between reputation and altruism.

Conflicts of interest: none.

Acknowledgements: We would like to thank Dr. Yuji Ogihara for his helpful comments on earlier versions of this manuscript. We also thank our colleagues at Kyoto University for the insightful discussions. This work was supported by Grant-in-Aid for JSPS Research Fellow [16J11139] in the data collection and English proofreading.

Appendix A. Supplementary data: Supplementary data to this article can be found online at http://dx.doi.org/10.1016/j.paid.2017.09.003. 


\section{References}

Arnocky, S., Piche, T., Albert, G., Ouellette, D., \& Barclay, P. (2017). Altruism predicts mating success in humans. British Journal of Psychology, 108, 416-435. doi:10.1111/bjop.12208

Barclay, P. (2010). Altruism as a courtship display: some effects of third-party generosity on audience perceptions. British Journal of Psychology, 101, 123-135. doi:10.1348/000712609X435733

Barclay, P. (2012). Harnessing the Power of Reputation: Strengths and Limits for Promoting Cooperative Behaviors. Evolutionary Psychology, 10, 868-883. doi:10.1177/147470491201000509

Barclay, P., \& Willer, R. (2007). Partner choice creates competitive altruism in humans. Proceedings of the Royal Society B: Biological Sciences, 274, 749-753. doi:10.1098/rspb.2006.0209

Batson, C. D. (2011). Altruism in humans. USA: Oxford University Press.

Bereczkei, T., Birkas, B., \& Kerekes, Z. (2007). Public charity offer as a proximate factor of evolved reputation-building strategy: an experimental analysis of a real-life situation. Evolution and Human Behavior, 28, 277-284. doi:10.1016/j.evolhumbehav.2007.04.002

Bereczkei, T., Birkas, B., \& Kerekes, Z. (2010). Altruism towards strangers in need: costly signaling in an industrial society. Evolution and Human Behavior, 31, 95-103. doi:10.1016/j.evolhumbehav.2009.07.004

Campbell, W. K., \& Foster, J. D. (2007). The narcissistic self: background, an extended agency model, and ongoing controversies. In C. Sedikides \& S. Spencer (Eds.), Frontiers in 
social psychology: The self (pp. 115-138). Philadelphia, PA: Psychology Press.

Davis, M. H. (1980). A multidimensional approach to individual differences in empathy. JSAS Catalog of Selected Documents in Psychology, 10, 85-103.

Fehr, E. (2004). Human behaviour: Don't lose your reputation. Nature, 432, 449-450. doi:10.1038/432449a

Fehr, E., \& Fischbacher, U. (2003). The nature of human altruism. Nature, 425, 785-791. doi:10.1038/nature02043

Hamilton, W. D. (1964). The genetical evolution of social behaviour. Journal of theoretical biology, 7, 1-52.

Hardy, C. L., \& Van Vugt, M. (2006). Nice guys finish first: the competitive altruism hypothesis. Personality and Social Psychology Bulletin, 32, 1402-1413. doi:10.1177/0146167206291006

Hashimoto, H., \& Yamagishi, T. (2013). Two faces of interdependence: Harmony seeking and rejection avoidance. Asian Journal of Social Psychology, 16, 142-151. doi:10.1111/ajsp.12022

Herrmann, B., Thoni, C., \& Gachter, S. (2008). Antisocial punishment across societies. Science, 319, 1362-1367. doi:10.1126/science.1153808

Himichi, T., Osanai, H., Goto, T., Fujita, H., Kawamura, Y., Davis, M. H., \& Nomura, M. (2017). Development of a Japanese version of the Interpersonal Reactivity Index. The Japanese journal of psychology, 88, 61-71. doi:10.4992/jjpsy.88.15218

Izuma, K., Matsumoto, K., Camerer, C., F., \& Adolphs, R. (2011). Insensitivity to social reputation in autism. Proceedings of the National Academy of Sciences, 108, 1730217307. doi:10.1073/pnas. 1107038108 
Kawamura, Y., \& Kusumi, T. (2017). The norm-dependent effect of watching eyes on donation. Evolution $\quad$ and Human Behavior, $38, \quad 659-666$. doi:10.1016/j.evolhumbehav.2017.05.003

Kojima, Y., Ohta, K., \& Sugawara, K. (2003). Praise seeking and rejection avoidance need scales: Development and examination of validity. The Japanese Journal of Personality, 11, 86-98.

Konrath, S. H., Ho, M.-H., \& Zarins, S. (2016). The Strategic Helper: Narcissism and Prosocial Motives and Behaviors. Current Psychology, 35, 182-194. doi:10.1007/s12144-016-9417-3

Konrath, S. H., O'Brien, E. H., \& Hsing, C. (2011). Changes in dispositional empathy in American college students over time: a meta-analysis. Personality and Social Psycholology Review, 15, 180-198. doi:10.1177/1088868310377395

Lin-Healy, F., \& Small, D. A. (2012). Cheapened altruism: Discounting personally affected prosocial actors. Organizational Behavior and Human Decision Processes, 117, 269274. doi:10.1016/j.obhdp.2011.11.006

Milinski, M., Semmann, D., \& Krambeck, H. J. (2002). Reputation helps solve the 'tragedy of the commons'. Nature, 415, 424-426. doi:10.1038/415424a

Oda, R., Dai, M., Niwa, Y., Ihobe, H., Kiyonari, T., Takeda, M., \& Hiraishi, K. (2013). SelfReport Altruism Scale Distinguished by the Recipient (SRAS-DR): validity and reliability. The Japanese journal of psychology, 84, 28-36. doi:10.4992/jjpsy.84.28

Oda, R., Machii, W., Takagi, S., Kato, Y., Takeda, M., Kiyonari, T., . . Hiraishi, K. (2014). Personality and altruism in daily life. Personality and Individual Differences, 56, 206-209. doi:10.1016/j.paid.2013.09.017 
Oda, R., Niwa, Y., Honma, A., \& Hiraishi, K. (2011). An eye-like painting enhances the expectation of a good reputation. Evolution and Human Behavior, 32, 166-171. doi:10.1016/j.evolhumbehav.2010.11.002

Oda, R., Shibata, A., Kiyonari, T., Takeda, M., \& Matsumoto-Oda, A. (2013). Sexually dimorphic preference for altruism in the opposite sex according to recipient. British Journal of Psychology, 104, 577-584. doi:10.1111/bjop.12021

Parks, C. D., \& Stone, A. B. (2010). The desire to expel unselfish members from the group. Journal of Personality and Social Psychology, 99, 303-310. doi:10.1037/a0018403

Phillips, T., Barnard, C., Ferguson, E., \& Reader, T. (2008). Do humans prefer altruistic mates? Testing a link between sexual selection and altruism towards non-relatives. British Journal of Psychology, 99, 555-572. doi:10.1348/000712608X298467

Piazza, J., \& Bering, J. M. (2008). Concerns about reputation via gossip promote generous allocations in an economic game. Evolution and Human Behavior, 29, 172-178. doi:10.1016/j.evolhumbehav.2007.12.002

Rege, M., \& Telle, K. (2004). The impact of social approval and framing on cooperation in public good situations. Journal of Public Economics, 88, 1625-1644. doi:10.1016/s0047-2727(03)00021-5

Sylwester, K., \& Roberts, G. (2010). Cooperators benefit through reputation-based partner choice in economic games. Biology Letters, 6, 659-662. doi:10.1098/rsbl.2010.0209

Trivers, R. L. (1971). The evolution of reciprocal altruism. The Quarterly review of biology, $46,35-57$.

Wu, J., Balliet, D., \& Van Lange, P. A. M. (2016a). Reputation management: Why and how gossip enhances generosity. Evolution and Human Behavior, 37, 193-201. 
doi:10.1016/j.evolhumbehav.2015.11.001

Wu, J., Balliet, D., \& Van Lange, P. A. M. (2016b). Reputation, Gossip, and Human Cooperation. Social and Personality Psychology Compass, 10, 350-364. doi: $10.1111 / \mathrm{spc} 3.12255$ 
Table. 1. Means, Standard Deviations, Coefficient Alphas, and Correlations $(N=416)$.

\begin{tabular}{|c|c|c|c|c|c|c|c|c|c|c|c|c|c|c|c|c|c|c|c|c|c|}
\hline & & Measure & $M$ & $S D$ & $\alpha$ & 1. & & 2. & & 3. & & 4. & & 5. & & 6. & & 7. & & 8. & \\
\hline 1 . & IRI & Fantasy Scale & 3.10 & 0.66 & .79 & - & & & & & & & & & & & & & & & \\
\hline 2 . & & Perspective taking & 3.05 & 0.48 & .60 & .20 & $* * *$ & - & & & & & & & & & & & & & \\
\hline 3. & & Empathic Concern & 3.28 & 0.50 & .69 & .25 & $* * *$ & .33 & $* * *$ & - & & & & & & & & & & & \\
\hline 4. & & Personal Distress & 3.09 & 0.55 & .71 & .32 & $* * *$ & -.10 & $*$ & .12 & $*$ & - & & & & & & & & & \\
\hline 5 . & PSRA & Praise Seeking & 2.74 & 0.71 & .88 & .24 & $* * *$ & .13 & $* *$ & .02 & & .02 & & - & & & & & & & \\
\hline 6. & & Rejection Avoidance & 3.24 & 0.71 & .88 & .26 & $* * *$ & .07 & & .11 & $*$ & .55 & $* * *$ & .18 & $* * *$ & - & & & & & \\
\hline 7. & SRAS-DR & Family members & 3.59 & 0.83 & .84 & .09 & $\dagger$ & .15 & $* *$ & .29 & $* * *$ & -.04 & & .08 & & .02 & & - & & & \\
\hline 8 . & & Friends/acquaintances & 3.20 & 0.74 & .82 & .16 & $* *$ & .22 & $* * *$ & .32 & $* * *$ & -.03 & & .14 & $* *$ & .07 & & .60 & $* * *$ & - & \\
\hline 9. & & Strangers & 2.19 & 0.86 & .86 & .09 & $\dagger$ & .20 & $* * *$ & .17 & $* * *$ & -.15 & $* *$ & .23 & $* * *$ & -.17 & $* * *$ & .39 & $* * *$ & .43 & $* * *$ \\
\hline
\end{tabular}

Notes. $\dagger p<.10 ; * p<.05 ; * *<.01 ; * * *<.001 . \quad$ IRI $=$ Interpersonal Reactivity Index; PSRA = Praise Seeking and Rejection

Avoidance Need Scales; SRAS-DR = Self-Report Altruism Scale Distinguished by the Recipient. 
Table. 2. Hierarchical multiple linear regression predicting altruism from the age, gender, empathy, and reputational concern $(N$ $=416)$.

\begin{tabular}{|c|c|c|c|c|c|c|c|c|c|c|c|c|c|c|c|c|c|c|}
\hline & \multicolumn{6}{|c|}{ Family members } & \multicolumn{6}{|c|}{ Friends/acquaintances } & \multicolumn{6}{|c|}{ Strangers } \\
\hline & \multicolumn{3}{|c|}{ Step 1} & \multicolumn{3}{|c|}{ Step 2} & \multicolumn{3}{|c|}{ Step 1} & \multicolumn{3}{|c|}{ Step 2} & \multicolumn{3}{|c|}{ Step 1} & \multicolumn{3}{|c|}{ Step 2} \\
\hline & $\beta$ & $95 \% \mathrm{CI}$ & $p$ & $\beta$ & $95 \% \mathrm{CI}$ & $p$ & $\beta$ & $95 \% \mathrm{CI}$ & $p$ & $\beta$ & $95 \% \mathrm{CI}$ & $p$ & $\beta$ & $95 \% \mathrm{CI}$ & $p$ & $\beta$ & $95 \% \mathrm{CI}$ & $p$ \\
\hline $\operatorname{Sex}(M: 1, F: 2)$ & .13 & {$[.03, .22]$} & .009 & .13 & {$[.04, .23]$} & .006 & .28 & {$[.19, .37]$} & $<.001$ & .29 & {$[.20, .38]$} & $<.001$ & -.02 & {$[-.12, .08]$} & .683 & .01 & {$[-.09, .10]$} & .889 \\
\hline Age & .11 & {$[.02, .20]$} & .020 & .12 & {$[.03, .22]$} & .011 & -.22 & {$[-.31,-.13]$} & $<.001$ & -.21 & {$[-.30,-.12]$} & $<.001$ & .14 & {$[.05, .24]$} & .003 & .14 & {$[.05, .23]$} & .003 \\
\hline Fantasy Scale & .04 & {$[-.06, .14]$} & .418 & .02 & {$[-.08, .12]$} & .713 & .06 & {$[-.03, .15]$} & .213 & .03 & {$[-.06, .13]$} & .514 & .11 & {$[.01, .21]$} & .036 & .06 & {$[-.04, .16]$} & .267 \\
\hline Perspective Taking & .05 & {$[-.05, .15]$} & .288 & .04 & {$[-.06, .14]$} & .399 & .10 & {$[.00, .19]$} & .040 & .09 & {$[-.01, .18]$} & .067 & .13 & {$[.03, .23]$} & .012 & .13 & {$[.03, .23]$} & .010 \\
\hline Empathic Concern & .24 & {$[.14, .34]$} & $<.001$ & .24 & {$[.14, .35]$} & $<.001$ & .26 & {$[.16, .35]$} & $<.001$ & .26 & {$[.17, .36]$} & $<.001$ & .11 & {$[.01, .22]$} & .029 & .13 & {$[.03, .22]$} & .013 \\
\hline Personal Distress & -.09 & {$[-.19, .01]$} & .067 & -.11 & {$[-.22, .01]$} & .069 & -.15 & {$[-.25,-.06]$} & .001 & -.15 & {$[-.26,-.04]$} & .006 & -.16 & {$[-.26,-.06]$} & .002 & -.05 & {$[-.16, .07]$} & .408 \\
\hline $\begin{array}{l}\text { Praise Seeking } \\
\text { Rejection }\end{array}$ & & & & .08 & {$[-.01, .18]$} & .093 & & & & .11 & {$[.02, .20]$} & .016 & & & & .25 & {$[.15, .34]$} & $<.001$ \\
\hline Avoidance & & & & .03 & {$[-.08, .15]$} & .545 & & & & .01 & {$[-.10, .11]$} & .916 & & & & -.20 & {$[-.31,-.09]$} & $<.001$ \\
\hline$\Delta \mathrm{R}^{2}$ & & & & .01 & & & & & & .01 & $*$ & & & & & .07 & $* * *$ & \\
\hline $\mathrm{R}^{2}$ & .12 & $* * *$ & & .13 & $* * *$ & & .24 & $* * *$ & & .26 & $* * *$ & & .10 & $* * *$ & & .17 & $* * *$ & \\
\hline
\end{tabular}

Note: ${ }^{*} p<.05 ; * * * p<.001 . \quad \mathrm{CI}=$ confidence interval for $\beta$. 